\title{
EDUCAÇÃO DO LUGAR: SAÚDE MENTAL E PEDAGOGIA DA CIDADE
}

\section{EDUCATION OF THE PLACE: MENTAL HEALTH AND PEDAGOGY OF THE CITY}

\section{Maria Cristina Carvalho da Silva}

Mestre e doutoranda em

Educação (Educação em Saúde)

na Universidade Federal do Rio

Grande do Sul, coordenadora

executiva da Residência Integrada

Multiprofissional em Saúde Mental

Coletiva na UFRGS.

\section{Ricardo Burg Ceccim}

Doutor em Psicologia Clínica e PósDoutor em Antropologia Médica. Professor Titular na Área de Saúde Coletiva da Universidade Federal do Rio Grande do Sul.

\section{Porto Alegre: a nossa cidade e a saúde mental coletiva}

Em Porto Alegre, na década de 1990, na implantação do Sistema Único de Saúde (SUS), a rede própria municipal de saúde era constituída por 09 Unidades Básicas, 01 Unidade de Saúde de Referência (atenção em especialidades) e o Hospital Municipal de Pronto Socorro. Em um processo desencadeado como municipalização da saúde uma reorganização tecnoassistencial abrangente de todos os serviços de saúde existentes na cidade, bem como a aplicação dos princípios e diretrizes do SUS no planejamento, avaliação e condução das ações cotidianas de saúde foram desafios assumidos no plano de governo e motivo para a recomposição dos quadros de gestão, para a realização de concursos públicos, para o planejamento de reformas prediais e para a mobilização popular tendo em vista a composição de conselhos e a realização de conferências de saúde.

O primeiro serviço próprio municipal em saúde mental foi a Pensão Pública Protegida Nova Vida, iniciando suas atividades no ano de 1990 em um esforço de não deixar reingressar na internação psiquiátrica pública um grupo de 53 cidadãos que

\footnotetext{
' O presente texto mantém uma estrutura diversa, não tendo todos os elementos previstos nas diretrizes da revista, pois o objetivo foi respeitar a originalidade do texto, escrito em 2010. Este texto foi selecionado e publicado em homenagem a Maria Cristina Carvalho da Silva, pesquisadora e incansável militante da Reforma Psiquiátrica, em especial no Rio Grande do Sul, que faleceu no dia 08 de setembro de 2012, em Porto Alegre/RS.
} 
perderiam seu vínculo de usuários em uma clínica privada pelo descredenciamento com a previdência social. Foi o primeiro serviço da rede de saúde mental da cidade de Porto Alegre. Experiência da qual resultou, no período mais recente, a atual Oficina de Geração de Renda - espaço protegido de trabalho para ampliar a sustentabilidade e conferir autonomia individual/coletiva aos seus participantes - e o Centro de Atenção Integral à Saúde Mental do Distrito Sanitário no 8 ou Centro de Atenção Integral à Saúde Mental da região Centro (Cais Mental Centro), reconhecido, pelas atuais normativas nacionais, como Centro de Atenção Psicossocial (Caps).

Quando da preparação e realização da I Conferência Municipal de Saúde Mental, em 1992, percorreu-se a cidade, promovendo a discussão sobre saúde mental, diversidade e direito à cidade, o que permitiu colocar em questão os paradigmas da saúde e da doença, da loucura e da exclusão, da cidadania e dos direitos sociais. No contato com os bairros ou onde houvesse grupos organizados, tais como Associações de Moradores, Círculos de Pais e Mestres, Clubes de Mães, Clubes da Terceira Idade e Conselhos Locais de Saúde surgiam cidades dentro da cidade. Outras cidades, lugares feitos de pessoas, suas histórias de dor e sofrimento, suas histórias de resistência e solidariedade, sua pressão sobre a cidade "das instituições" e uma educação da cidade, auto-organização de pessoas e grupos para forjar lugares de existência ou resistir às serializações urbanas; composição de coletivos, ora determinados desde a cidade, ora linhas de enlace social em cidades sem geografia, redes de contatos, redes de afetos, redes de invenção de cidades de proteção, suporte $e$ inclusão.

No período entre 1993 e 1995 ocorreu a implantação de equipes de saúde mental por distritos de saúde da cidade, segundo o modelo de Centros de Atenção
Integral em Saúde Mental (Cais Mental), o primeiro foi instalado na Vila Cruzeiro, região de periferia, na orientação centro-sul da cidade, ocupando a área física de uma grande unidade do Instituto Nacional de Assistência Médica da Previdência Social, região protagonista das lutas por saúde na capital.

Nessa brevíssima síntese, anotamos ainda que o movimento da Reforma Sanitária, com a consolidação do SUS, articulava-se com o movimento da Reforma Psiquiátrica, em curso no país. Em Porto Alegre, o tema da gestão em saúde era o carro chefe e a produção de conhecimentos e práticas em saúde mental - no bojo da reforma psiquiátrica - estava representada pelo Fórum Gaúcho de Saúde Mental. O encontro da gestão em saúde orientada pela implantação do SUS e o movimento social pela saúde mental protagonizaram a montagem da Rede de Atenção Integral em Saúde Mental, iniciativa para que o sistema de saúde viesse responder aos desafios contemporâneos na área e às necessidades das pessoas em situação de sofrimento psíquico. A Rede de Atenção Integral em Saúde Mental articulava ensino-serviçogestão-participação em uma composição entre psicanálise, educação e saúde coletiva, campo de domínio do conhecimento e roteiro de práticas designado por Saúde Mental Coletiva e capaz de discutir a clínica da atenção psicossocial e a produção cultural das cidades subjetivas (educação da cidade).

\section{A saúde mental e a descoberta da educação do lugar: a emergência de zonas na luta pela liberdade de subjetivação na cidade}

Desencadeado o processo de oferta de uma rede de serviços em saúde mental 
substitutiva dos manicômios e distribuída pelas regiões da cidade e desencadeado o processo de elaboração de uma política municipal de saúde mental em contato com as redes da cidade que tramam cidades invisíveis, foi preciso viver intensamente a atenção psicossocial em seus centros e equipamentos assistenciais para descobrir o "lado de fora". Depois de nos propormos a fechar os manicômios, de abrirmos serviços substitutivos e de inserirmos pessoas com a vivência de transtorno psíquico em redes de acolhimento em saúde, uma nova pergunta, a pergunta sobre o tramado das cidades, de suas redes tradicionais em Associações, Círculos, Conselhos etc. às redes contemporâneas, que já são redes de redes e em redes. Desinstitucionalizar é o mesmo que dessegregar? Dessegregar é estender a clínica às redes sociais de inclusão ou é fazer emergir as cidades da cidade em novas tramas, novos valores, novas humanidades? Desejamos uma "alta" da clínica ou a vinculação permanente aos serviços da clínica, de modo que nossos usuários assim o sejam para sempre, como na obtenção de uma etiqueta de filiação preferencial? Por que não somos local de referência para a cidade, apenas referência para usuários encaminhados ou inscritos? Passamos a perceber que há necessidade de cidades de acolhimento e heterogênese para uma real "alta" da clínica. Quando se obtém a "alta" dos serviços de saúde ou o diploma na escola, supõe-se conquista de autonomia para habitar a cidade, em suas redes sociais, de trabalho e de lazer. Precisamos, então, dar alta e de uma pedagogia das cidades para que cidades possam se fazer, possam emergir, possam se territorializar para estes que obtiveram a alta. Cidades se tornando cidade como efeito dos encontros da clínica com uma educação da cidade.

Se a cidade é a esfera da política (polis), é a esfera da produção política das cidades, das suas redes sociais, dos desafios de pensamento e da ativação de práticas.
A aposta em uma pedagogia da cidade agrega tramas intersetoriais, é a aposta na construção de aprendizagens por redes de encontro, estabelecimento de laços sociais, emergência de territórios por comunidade de afetos com a vida, é a aposta em uma pedagogia da zona, uma educação do lugar. Aceita-se a cidade com suas cidades, aceitase as zonas que compõem as cidades, que delas precisam para serem cidades no contemporâneo. Uma educação do lugar, então, não é algo que se impõe, é algo que emerge, emerge das forças de resistir e criar.

Aqui destacamos o conceito de saúde como capacidade de afirmar a vida e a educação como o estabelecimento de redes e fluxos de afirmação da vida ${ }^{1}$ para colocarmos educação e saúde como construtoras de mais vida, zonas de mais vida. A educação do lugar ou a pedagogia da zona como pedagogia da cidade, cidade de zonas de invenção da saúde. A saúde é "a capacidade de se gerar mais vida com o caminhar na vida" ou, ainda, "a capacidade de indivíduos e coletivos gerarem redes que atam vida e como tal produzem-na." 2:31 Essa é uma pedagogia da cidade, educação do lugar, espécie de pedagogia de zona. Para nós, a oportunidade de uma saúde mental em produção na zona e por zonas, no interior das redes sociais contemporâneas, onde a atenção psicossocial participa como nó ou enlace intersetorial, contribuindo à invenção das cidades invisíveis de dessegregação e inclusão, de desinstitucionalização e liberdade às subjetivações, de ressingularização permanente, de trama criativa pela aposta na vida.

Uma "alta" da clínica implica a demonstração de sua potência e o desvelamento de seus limites, limites estes que, no encontro com a educação da cidade apontariam para uma cidade que dá lugar, inclusiva e porosa à alteridade. 


\section{Pedagogia da cidade ou educação}

\section{do lugar e a saúde mental na zona}

$\mathrm{O}$ que queremos introduzir com a noção de uma pedagogia da cidade é a compreensão da necessidade de produzir e operar fora das redes instituídas de cuidado à saúde, ver o seu fora e, ali ou aí, assumir a retomada dos processos de subjetivação, inclusive processos intensivos de vida e desrazão. A educação do lugar se apresenta, então, como desafio às saúdes e à ativação de pensamento pelos abalos do fora sobre o território estruturado da atenção psicossocial nos serviços de saúde mental. Trata-se da aventura inicial pelas "zonas de fronteira", fronteira entre os serviços de atenção psicossocial e as ruas da cidade. As ruas da cidade como a cultura da cidade, suas zonas de resistir e criar e suas redes sociais nas quais o contemporâneo está recriando as cidades. Na noção de educação do lugar, assumimos os percursos que se efetuam, os discursos que se pronunciam e as linguagens que ganham destaque. A cidade, seus ritmos, pulsações, contradições e configurações constituem processualidades produtoras de subjetividade.

Brissac $^{3}$ chama a atenção para a multidão "que aprendeu a navegar no mar aberto, no novo terreno: móvel no espaço e flexível no tempo." O autor destaca, na multidão, sua absoluta mobilidade, emergência das populações errantes, populações pendulares, populações que têm na migração a sua condição de existência e que vivem, literalmente, em movimento, ao longo de fluxos. Um mundo onde "se nasce numa clínica e se morre num hospital" e onde "se multiplicam, em modalidades luxuosas ou desumanas", os pontos de trânsito e as ocupações provisórias, das cadeias de hotéis aos terrenos invadidos, dos clubes de férias aos acampamentos de sem-teto, dos condomínios-bairro da elite econômica às favelas destinadas aos desempregados. O fascínio que as grandes cidades exercem decorre, em parte, do fato de nelas se mesclarem a transparência dos olhares panópticos e a opacidade das rebeldias.

As rebeldias proliferam nos pontos cegos, "nos avessos e interstícios". 4:167 Assim, as rebeldias nascidas nos interstícios, nos becos, nas zonas, vão, em movimentos infinitesimais, crescentes, ganhando terreno, como ervas daninhas que crescem entre o asfalto e o concreto da cidade. Rizomas que, disseminados, vêm à luz e configuram novas visibilidades na cidade, solapando a ordem no cotidiano. Zonas! A zona do meretrício, a zona do tráfico, a zona da boemia... Zonas definidas por aqueles que as ocupam e zonas que demarcam perímetros na cidade esquadrinhada, do centro à sua periferia.

Outro sentido para Zona, hoje, é que tudo pode ser desacomodado e pode virar "uma zona". Zonas podem ser o caos ou a singularização. Zonas podem ser resistência ou esconderijo. Zonas podem ser adensamento de diversidades ou das singularidades que a multidão comporta. Singularidades não se esvanecem quando reunidas em um só tempo e lugar. Num movimento criativo, se constituem como uma zona. O singular e o diverso precisam de sua zona de existir, de resistir. A zona de fronteira é lugar de distinção entre diversos e, a um só tempo, lugar de encontro, possibilidade de contágio e mestiçagem. Emergência do coletivo de zona. No caso da fronteira entre a atenção psicossocial e a rede cultural da rua, a pedagogia que daí deriva, abandona a normalização e a prescrição, lança-se nos espaços de criação e de invenção das cidades.

Provisoriamente, falamos em pedagogia da cidade e observamos os laços sociais que produzem a atenção em saúde mental (e sua clínica psicossocial) e a educação em saúde mental (e seus enlaces 
na cultura). A capacidade de "gerar mais vida com o caminhar na vida" e a capacidade de indivíduos e coletivos "gerarem redes que atam vida e assim produzirem-na" são as alavancas para encetar zonas, aprender a pedagogia da zona por meio da qual temos acesso às cidades da cidade e podemos buscar liberdade e singularização. Educação do lugar, prefigurada no reconhecimento dos processos totalizadores ou de homogeneização e sua crítica, que tem como pressuposto a noção de alteridade e se realiza no compromisso radical com o outro como princípio ético de afirmação da vida.

Jacques" 5:121 no texto "Elogio aos errantes: a arte de se perder na cidade", propõe a errância urbana como apologia da experiência da cidade, em oposição à educação do urbanismo, voltada para a questão da orientação, "do se orientar", ou seja, o "contrário mesmo de se perder". Os praticantes das cidades, aqueles que a experimentam no cotidiano, os que realizam "apropriações ou improvisações", habitantes, passantes ou errantes, reinventam a cidade no seu cotidiano. Há, na errância, um elemento de resistência que remete ao corpo, à expressão da corporeidade em interação com a cidade. A autora descreve três propriedades da errância: "se perder, lentidão, corporeidade." Estas estão relacionadas "à própria ação, ou seja, à prática ou experiência do espaço urbano." O ato do errante, de se relacionar com a cidade, "implica uma corporeidade própria, advinda da relação entre seu próprio corpo físico e o corpo urbano, que se dá no momento da desterritorialização lenta da errância." A errância, considerando essas três propriedades, resiste tanto "ao pensamento hegemônico contemporâneo do urbanismo" como à atual "especularização" dos espaços urbanos, que levam à "redução da experiência e presença física", utilizando as tecnologias de comunicação e transporte, que visam à "orientação (principalmente pelo excesso de informação) e rapidez (ou aceleração)". São as pessoas, portanto, que, nos seus percursos pela cidade, ao experimentarem os espaços, "Ihes dão corpo e vida, pela simples ação de percorrê-los." Com os percursos dos errantes a cidade deixa de ser "simples cenário" porque está sendo vivida e experimentada. A cidade, na interação, "ganha corpo". Corpo como efeito desta interação: "é do corpo do cidadão e deste outro corpo urbano que poderia surgir outra forma de apreensão da cidade", uma forma errante, uma forma de ação "desorientada, lenta e incorporada." 5:127 Para o errante, a lentidão é o seu tipo de movimento, uma postura. Trata-se de uma corporeidade ou de um 'espírito de corpo' que nasce da desterritorialização.

Inês, a quem acompanhamos, por algum tempo, dizia: "depois do evento, sabe... Aquele... Há uma outra em mim, às vezes, faço de conta que não está ali, mas é sombra, é minha própria sombra, me acompanha aonde vou, está onde estou". Inês participa de atividades em um ateliê de artes da cidade e, quando não está satisfeita com sua produção, diz: "Quando pinto é ela que borra as minhas formas". Refere que, quando está caminhando na rua para escapar da outra, só anda nas calçadas onde há sombra dos edifícios, das casas ou das árvores: "até não me importo muito, mas, às vezes, durante o dia, só ando pela sombra, fica meio complicado, as pessoas não entendem bem, acham que não estou bem certa. Mal sabem elas!" (risos). Ou ainda, João, que vivia muito bem onde pudesse pisar na terra. Diz que se desorienta na cidade, quando há só asfalto, sente que perde a conexão (conexão com a terra, com as coisas da terra, com o chão, com o cosmos) e, então, precisa ficar se tocando para sentir que está ali. O problema, diz ele, "é que acho que todo mundo fica olhando, às vezes tenho que voltar rápido para casa, se não há uma praça, um verde por perto". 
Nora mora na rua, junto a um lago, próximo de uma grande avenida. No verão, lava suas roupas e, às vezes, se banha neste lago. Costuma cantar quando faz isso. Fica de calcinha e sutiã. Indignada, pergunta para os passantes que param para olhar: "Não têm mais nada, não, para fazer, do que ficar bisbilhotando a vida dos outros?" Esbraveja: "Não tem vergonha, não?" Para ela, são eles, os passantes, que, ao olharemna, a invadem, atrapalham, perturbam um momento de sua intimidade: a hora do banho e de lavar suas roupas! Mesmo que este momento aconteça no lago, na praça, junto à grande avenida, no centro da cidade. Seu Otacílio, participante ativo das reuniões da Associação de Moradores de seu bairro, em algum momento, durante a reunião, pede a palavra, inicia com uma intervenção pertinente ao assunto e, na sequência, começa a contar do seu encontro com os anjos e das mensagens a ele destinadas. Sua voz e postura mudam. Transmite a mensagem e, quando termina, agradece a atenção recebida, senta e volta a participar da reunião, tranquilamente.

Da zona de loucos, do espaço fechado do manicômio, passando pelos serviços de atenção em saúde mental para as ruas da cidade, antevemos, agora, não apenas a clínica psicossocial na rua, mas a própria rua, após um direito conquistado à alta. Os espaços e tempos da cidade, em muitos casos, são estranhos. A velocidade, os modos de diferenciação e demarcação de espaços e lugares, a cronologia da agenda, dos compromissos, a lógica da produção, do mercado e do consumo. Para muitos, tratase de um imenso esforço, de uma aventura, a realização de pequenos atos prosaicos do cotidiano. Acordar pela manhã e se ocupar da higiene pessoal, ir às compras, escolher o que comprar e identificar o quanto pode comprar com o dinheiro que dispõe; pegar um ônibus, se localizar no espaço e no emaranhado de pessoas, carros e ruas. Tratase, enfim, de um modo muito particular de habitar a cidade, um modo, às vezes, errante, claudicante, lento e desorientado ou, ainda, distraído. Outras vezes, é a agitação, a excitação, a perplexidade diante do movimento que agita e desorienta. Fazer caber estes modos de estar e habitar a cidade, respeitando as suas particularidades e valorizando a singularidade é algo que pode se tornar possível numa cidade morada do diverso - na qual a educação do lugar comparece e interroga a demarcação dos espaços e tempos do viver em comum.

A forma desorientada e lenta de experimentar a cidade, avessa ao modo hegemônico, essa forma errante, comporta, ela mesma, uma pedagogia, um ato que convoca à aprendizagem no convívio, na interação. A zona de loucos já não está demarcada pelo não lugar (o lugar dessingularizado do hospício), é a mesma para seus ocupantes errantes de qualquer tipo, expoentes da vida, confundem-se e fazem zonas de compartilhamento. Quantos habitantes de cidades já não viveram a experiência da desorientação, não foram afetados pelas sensações, pela vertigem que a perda de referências produz? Quantos já não viveram a desterritorialização, diante do, aparentemente familiar, que irrompe em estranheza, na sua própria cidade, quando adentram territórios novos e desconhecidos, até então inexplorados? Esta é uma experiência que a cidade multifacetada, a cidade que não conseguimos apreender na totalidade, permite a cada um. Territórios existenciais que se afetam, se encontram, na forma delicada de um toque ou brusca de um choque se disseminam em redes e conexões, se fazem com o andar da vida na cidade, configuram pedagogias de zona: zonas de comunidade, zonas de estranhamento, zonas de interação, zonas de transformação.

Na zona, singularidade e comunidade se revezam. Na comunidade, a interação e o compartilhamento, motivo para a singularidade. $\mathrm{Na}$ singularidade, a 
diferenciação e a criação, motivo para a comunidade. Para Inês, João, Nora e Otacílio, a cidade, ela mesma, na materialidade da qual se constitui - pedra, espaço, asfalto, terra, multidão, encontros e interações - tem função de alteridade, permite a exposição de si, a experiência do contato e a fruição. Configura possibilidades de experiência para além do repertório delimitado, tanto, pelos serviços de saúde, onde já há certa espera de determinados comportamentos, quanto pela família, para a qual, proteção e cuidado, muitas vezes, significam limitar as expectativas quanto às possibilidades de autonomia e devir. Para Otacílio, participar da Associação de Moradores de seu bairro significa exercer sua cidadania, buscando contribuir para a solução dos problemas de seu bairro. Tornou-se um líder no bairro. Bairro que passou a respeitá-lo, por sua dedicação às causas do lugar. Os participantes da Associação se habituaram aos "improvisos", quando Otacílio interrompe o fluxo de idéias pertinentes ao tema da reunião, para transmitir "as mensagens". Consideram que, muitas vezes, "não são assim tão sem sentido". Quem aprendeu com quem? Quem ganhou em humanidade e solidariedade? Os demais integrantes da Associação de Bairro ou Seu Otacílio? Um e outro, na interação? Otacílio dedica-se ao lugar, cria um lugar e é acolhido por esse lugar.

Para João sair de casa - mora num pequeno sítio afastado do centro da cidade - é necessário um ritual, que ele cumpre como precaução aos possíveis efeitos do asfalto sobre a sua capacidade de conexão. Com isto, como parte do ritual, voltou a falar e escrever em alemão, língua que aprendeu na infância. Enquanto anda pela cidade, fala em alemão, baixinho, sussurrando. 0 som das palavras em alemão o acalmam. Não tinha com quem falar e exercitar a língua, falava sussurrando em alemão, enquanto andava, um monólogo que o ajudava a lidar com a angústia que lhe causava o asfalto e o concreto a sua volta. Numa dessas andanças pela rua, foi parar em frente a uma escola de línguas. $\mathrm{Na}$ entrada da escola, junto à calçada, um mural com propagandas e listas de organizações não-governamentais alemãs, dentre elas as de defesa do meio ambiente. Ficou interessado e escolheu passar em frente a este lugar em suas andanças. Não tinha coragem de entrar: muito concreto em volta, dizia. Então teve uma idéia, levou uma caderneta, anotou os dados de endereço das ONGs, escreveu algumas cartas, recebeu respostas e convites de pessoas de vários lugares do mundo que, como ele, falavam em alemão, defendiam a Terra e uma vida junto à natureza, engajando-se na luta pela preservação do meio ambiente. João, pouco afeito a vida de cidade, cruzou um lugar. Estar em contato com outras pessoas, escrever em alemão, comunicar-se e estar em sintonia com as baleias em extinção, com as araras azuis e com a floresta que precisa ser protegida Ihe conferiu a bem-vinda e efetiva sensação de conexão que tanto desejava.

Otacílio, João, Inês, Nora, Maria Cristina e Ricardo, singularidades que praticam lugares, entre outros, inventam mundo e a si mesmos. O processo educativo, assim, só pode ser imanente, relativo a quem o experimenta, porém, tributário das possibilidades e disponibilidades para 0 encontro com o outro.

Para a educação do lugar, essa pedagogia da zona é a proliferação da diversidade e da singularidade, que se faz em comunidade e ressingularização, sob efeitos de alteridade. No refrão do grupo de hip-hop Black Confusion, composto por jovens que freqüentaram serviços de atenção psicossocial, mais que um apelo, uma afirmação, uma palavra de ordem, que exige resposta: "O mundo lá fora precisa de mim, o mundo lá fora precisa de ti, não vamos deixar que calem nossa voz, o mundo precisa de nós." (2005) 
Pedagogias da cidade: as zonas de encontro

No cotidiano da produção de atos cuidadores em saúde mental, as tarefas de acolhimento, atendimento grupal, assistência individual intensiva, espaços de oficina e oportunidades de convívio ocorrem em redes de cuidado e são redes de encontro que podem gerar laços, conexões e lugares (para além daqueles circunscritos pelas instituições de saúde). Ativar redes de suporte e de circulação passa a ser tarefa do cuidado em saúde, em um cotidiano de atenção psicossocial. Se uma equipe de saúde é efetivamente equipe e cuida, ela própria é uma equipe em rede de conhecimentos e de práticas, em rede com redes sociais, equiperede. Uma equiperede se responsabiliza com o cuidado e se abre para encontros que transformam aqueles que cuidam e aqueles que são cuidados. Afetos, dores, impotência, angústia e incerteza estão lado a lado com as alegrias cotidianas diante de uma palavra que surge depois de longo mutismo, diante de um corpo marcado e mortificado que se reinventa num movimento inusitado. Detalhes aparentemente sem importância, que são índices de uma escuta de acolhimento e revelam a possibilidade de posse da cidade, inscrições num social que gera vida. Alguém que pela primeira vez sai às ruas e se descobre em um lugar, com nome e com poder para ir e vir pela cidade. A educação e a atenção em saúde mental se entrelaçam no espaço de rede de saúde e das redes sociais, onde operam os atos terapêuticos.

Um encontro surge como reinvenção do viver na relação com o outro, seja ele o amigo, o vizinho, o estranho, a praça, o ônibus, o cachorro, uma planta, outro que, na cidade, constitui enlaces culturais. Um encontro confronta, mobiliza. A produção de práticas terapêuticas e educativas é desafiada a levar em conta o movimento e o fluxo da vida na polis. Se assim for, possibilitam práticas orientadas para a conquista crescente da autonomia, agenciando múltiplos enlaces com o outro. No desenho das aproximações sucessivas, entre atenção e educação em saúde mental, a cidade, mais do que cenário no qual essas práticas ocorrem, representa a alteridade que afeta, desloca e transforma tais práticas.

Quando colocamos em questão a exclusão e os processos de segregação do louco (das existências em sofrimento), interrogamos a cidade, os seus lugares de inclusão e exclusão e aqueles considerados dentro da norma ou em estado de bemestar e aqueles de segregação ou em estado de contenção. $O$ tensionamento em relação aos lugares a serem praticados para/com os "loucos", coloca em cheque o ordenamento social vigente, as práticas coercitivas que visam a uma cidade disciplinar. A pergunta pela saúde mental interroga, profundamente, as cidades, sua produção de subjetividade e singularização. Uma cidade de cidadãos em série é a imagem da cidade de controle sobre a cidade de singularidades. A clínica psicossocial, como educação do lugar, ao buscar liberdade e singularização, produziria zonas em cujos domínios emergiriam confiança e acolhimento. Uma clínica e uma educação tributárias da experiência do encontro. A pedagogia que daí resulta será sempre plural, laços em redes, constituindo coletivos, subjetivando lugares.

O trabalho clínico, então, precisa ser repensado ou de alguma forma reforçado em sua potência desestabilizadora. A dimensão de acontecimento, como enuncia $\mathrm{Cabral}^{6}$, presente na clínica, entendido como um corte, uma ruptura, com aquilo que, de certo modo, paralisa e enclausura o sujeito em uma dada posição, traz em si um elemento transgressivo, já que subverte a lógica da inércia e da normalização. Os 
acompanhamentos individuais, os grupos, as oficinas, a permanência em centros de atenção diária ou em centros de convivência, mais que técnicas de intervenção, podem constituir dispositivos articulados e articuladores para novas produções de sentido. O trabalho da equiperede pode tecer a rede dos atos clínicos e os fios para laços sociais, encontrando aí, as pedagogias da cidade.

Quando há sofrimento e angústia, quando a subjetividade se fragmenta e se dispersa precisamos de cidades de acolhimento, cidades sensíveis, uma necessidade que converge para a educação do lugar, para a produção de relações sociais singularizadoras, inclusivas e afirmativas da vida.

Os Caps, diz Merhy ${ }^{2: 56}$, "por estarem no olho do furacão antimanicomial, tornaram-se lugares de manifestação de grandes conflitos e desafios", ousar dar conta de sua gigantesca missão é "estar aberto a operar no tamanho da sua potência e governabilidade, adotando como um dos princípios o de ser um dispositivo para isso", mas, nesse caso, nossa ação implicará "produzir novos coletivos, para fora de si mesmo." Produzir coletivos para fora de si mesmo está nos enlaces com o movimento social, com as redes sociais, com a cidade. Pedagogia da cidade: construção das zonas de encontro.

\section{Cartografias da zona: a educação do lugar}

A educação do lugar resulta do encontro entre saúde mental e cidade, percutindo como interrogantes. Situamos clínica e cidade, como experiência-limite, uma zona de clínica e uma zona de margens desterritorializadas, sugerindo a zona de fronteira da clínica com a cidade, como ocorre na atenção psicossocial e em uma pedagogia da zona. Sugerimos exposição, acolhimento, enfrentamento e construção de zonas. Toda zona é um território de possíveis ou de resistência e criação, toda zona comporta uma pedagogia da sua unidade e consistência. Por que não zonas de saúde mental coletiva, de modo a retirar a saúde mental dos domínios da psiquiatria, da psicofarmacologia, da psicopatologia, da internação, da clausura, do confinamento ou do vínculo permanente e obrigatório a um Caps? Nossa pergunta primeira foi: e a alta? Nossa pergunta seguinte foi: e a cidade? Chegamos às cidades dentro das cidades, os lugares, a invenção de lugares. No fora da clínica (sua abrangência disciplinar; sua supremacia na sociedade de controle das vidas e do viver), propusemos a educação do lugar (o conceito de processos educativos sobre a vida e o viver; a composição política dos coletivos nas multidões; a composição das zonas de comunidade que engendram confiança, acolhimento e afirmação).

Pudemos, então, detectar que quanto mais as redes sociais são ativadas e acolhem as pessoas em sua existência em sofrimento, tanto mais essas pessoas podem prescindir do espaço específico da atenção em saúde mental e passarem, gradativamente, a inserir seus projetos de vida em redes sociais diversificadas e plurais. Percebemos que as redes a que nos referimos como fundamentais para a "alta" dos/nos Caps são tecidas de diferentes formas e adquirem configurações muito próprias. Por vezes, trata-se de pontes entre um lugar e outro, como via de passagem.

O trabalho de ativador de redes pode ser também definido como a de construtor de pontes ou de costureiras artesanais, já que se trata de encontrar referências em condições e instituições que já existem, costurar tecidos e coser panos, couros etc.. A rede, na sua trama, consiste em proporcionar o acesso, criar caminhos, função por excelência do projeto Insere no 
Cais Mental, mas trata-se, em muitos casos, do ato de criação da rede, como no caso do Cinema em Debate. Criou-se uma rede que enlaça os serviços de saúde mental com espaços de cultura na cidade, uma rede que também inclui lugares de formação, como a Universidade, provocando aí uma reflexão sobre o trabalho em saúde mental, gerando pesquisas e desenvolvendo novas parcerias.

O Projeto Insere inclui atividades de cultura, educação, esporte, lazer e trabalho em parceria com entidades e agremiações sociais, esportivas e de lazer, viabilizando a participação dos usuários. No que se refere às atividades atinentes ao trabalho e à educação formal, foram realizadas parcerias com instituições formadoras (cursos profissionalizantes e técnicos, tais como manicure, marcenaria e tecelagem, dentre outros) até cursos de alfabetização para adultos e de formação de multiplicadores (um usuário, por exemplo, passou a ser o monitor do curso de alfabetização, destinado aos usuários com maior dificuldade de circulação na cidade, iniciado nas dependências do Cais Mental).

O Cinema em Debate é um projeto intersetorial desenvolvido com a parceria das secretarias estadual e municipal da cultura: sessões de cinema com a proposta de uma conversa após a exibição de filmes. A Casa de Cultura Mário Quintana, da Secretaria Estadual da Cultura, conta com filmes cedidos pela distribuidora Columbia Pictures e a Usina do Gasômetro, da Secretaria Municipal da Cultura, loca filmes para exibição na Sala Paulo Gastal. As sessões ocorrem a cada dois meses envolvendo os serviços de saúde mental de Porto Alegre e Região Metropolitana, destinados aos seus usuários e moradores das respectivas cidades. Hoje, faz parte de um trabalho conjunto de pesquisa entre Instituto de Psicologia, da Universidade Federal do Rio Grande do Sul, e os serviços de saúde mental das cidades envolvidas.
Depois destas experiências, destacamos o Caps como lugar de travessia, ao lado da função de acolhimento e hospitalidade para com a loucura. Para as pessoas em meio ao sofrimento psíquico intenso, acolher é também produzir ancoragens para que o encontro, na sua dimensão terapêutica, possa produzir novas significações, permitindo reconstruir a possibilidade de novos enlaces com o outro. Percebemos, ainda, que tais funções não esgotam o fazer clínico, nem a clínica recobre todo o fazer na atenção psicossocial. Situamos três momentos, movimentos ou funções fundamentais: acolhimento, confiança e singularização. Um quarto momento ou uma função que decorre das três primeiras, a função de enlace social, a educação do lugar. A função de enlace social se traduz tanto do ponto de vista da equiperede, quanto dos processos que possam resultar na substituição da instituição como referência ou até mesmo no seu desfazimento, onde ela deixa de ser necessária para seu egresso.

Experiências como a do Projeto Insere e do Cinema em Debate apontam para os efeitos do encontro da clínica com a cidade. Destacamos a presença dos atos pedagógicos nas funções de ativador de redes e mediador de relações e interações, necessário para a condução da clínica em lugares como os Caps. Queremos, agora, assinalar a diferença entre duas iniciativas que hoje operam em redes, não mais situadas como integrantes dos serviços de saúde mental, embora guardem relações de proximidade e intercâmbio com os mesmos. Trata-se do grupo Black Confusion e do Coletivo Potência Mental. O grupo Black Confusion nasceu no interior do Cais Mental Centro e, ao longo três anos, foi seu lugar de referência para os ensaios e produção musical. Gradativamente, foi ocupando lugares na cultura. Para seus participantes, representou o encontro com um potencial 
criativo até então desconhecido. Durante um determinado período ganhou estatuto de projeto intersetorial com recursos próprios e, aos poucos foram construídas outras referências, inclusive junto ao Movimento Negro da cidade. Suas apresentações públicas em eventos de Rap e Hip Hop o situaram como um grupo da cultura, com origem na saúde mental, esta convertida, pelo grupo, em símbolo de lutas e reivindicações. Converteram suas experiências de tratamento em emblemas com os quais marcam a sua presença no cenário cultural. São músicos, dançarinos, letristas que se definem e se apresentam como usuários de serviços de saúde mental, pessoas com vivências de sofrimento psíquico intenso, portadores de doença mental. Boa parte dos convites para apresentações ocorrem em eventos ligados ao campo da saúde em geral e da saúde mental em particular, ajudando a pensar conceitos e práticas desses setores.

O Coletivo Potência Mental nasceu de iniciativas referidas aos serviços, porém, sustentadas, inicialmente, por um curso de formação profissional especializada (Residência Integrada Multiprofissional em Saúde Mental Coletiva). Interage com outros movimentos e rádios - especialmente a Rádio Nikosia, de Barcelona, na Espanha, e com a Rádio Comunitária da Lomba do Pinheiro, em Porto Alegre - que ocupam lugares não referidos à rede assistencial de saúde, embora em rede de redes com a mesma. A zona de comunidade chega a um grau onde já não diferenciamos quem é usuário de serviço, quem é trabalhador ou profissional. Este desprendimento dos índices identitários, das insígnias - ser usuário, ser portador de doença mental ou ser trabalhador de serviço de saúde - que tão fortemente marcam os lugares sociais, os lugares de poder e os discursos de verdade, estão verdadeiramente, cotidianamente, sendo solapados, de uma maneira delicada, solta e alegre. Embora a questão da profissão possa fazer função para alguns, a exemplo do jornalista que se reencontrou como tal ao sair a pesquisar para produzir as matérias do programa, ela surge como dimensão de um trabalho, de um fazer que se expressa em um espaço de trocas e intercâmbios.

Márcio Belloc (2008)ii, referindo-se a sua experiência na Rádio Nikosia, salienta: o próprio fato de se estabelecer como uma associação cultural e não sanitária ou de usuários a apontaria para outra forma de estabelecer um protagonismo na luta pelos direitos e pela construção e cidadania dos afetados por problemas vinculados à saúde mental. Para ele, o fato de a rádio, desde a sua fundação, se colocar fora dos meios habituais de busca por estes direitos ocorre porque, deliberadamente, busca uma forma não clínica de construir saúde mental. Tomamos a afirmação de Márcio e a sua ênfase no "não-clínico", como um esforço para demarcar um limite e a heterogeneidade dos termos clínica e cidade. Somos levados a pensar que a experiência do Coletivo Potência Mental está na cultura de tal modo que aponta uma educação da cidade e do lugar.

$\mathrm{Se}$ nos referimos a lugares onde há implicação subjetiva, esses podem ser também designados como lugares da morada do híbrido, lugares mestiços, lugares aos quais nos reportamos a partir de uma implicação subjetiva, onde atualizamos nossas apostas no encontro com a alteridade-em-nós. Sabemos que, para os serviços de saúde, operar como rede é um passo importante, mas se configurarem como redes de serviços, redes disseminadas, redes de interação, não necessariamente referidas a uma instituição. Por redes, entendemos, a partir da concepção de Negri $^{7}$ e Ceccim ${ }^{8}$, uma trama disseminada e diversificada, tanto na sua materialidade como imaterialidade, resultado de possíveis configurações. Podemos pensá-la como

\footnotetext{
ii Depoimento recolhido em 2008.
} 
rizoma na sua capacidade de fluir, alargarse, cobrindo e recobrindo superfícies. Um determinado grupo de instituições ou serviços de saúde pode vir a configurar uma rede de cuidados, de acordo com o modo com que as pessoas interagem e operam. De maneira geral, os serviços de saúde operam como conjunto ou mesmo configuram uma coleção - daí a urgência da mudança nos processos de trabalho e nas práticas produzidas pelos serviços de saúde - onde as peças não necessariamente estabelecem relação umas com as outras, não interagem. No interior dessas instituições, para a sua própria existência, não podemos prescindir das pessoas, pois são elas que produzem, pelo seu trabalho, a relação de umas com as outras e com o seu fazer. O coletivo é o outro-em-nós e faz função de alteridade.

Trazemos aqui as palavras de Rafael Wolsky (2008)iii: percebo que essa é a força do coletivo, na rádio se produz saúde, se produz cultura, mídia, produção de saberes e amizade. Coletivizar é ir na contramão de uma tendência ensimesmada moderna, que pede cada vez mais enclausuramento e afastamento. É a potência política de um coletivo como o Potência Mental.

iii Depoimento recolhido em 2008.

\section{Fechamento}

Para não concluir, reiteramos nossa aposta e nosso desafio, levados pelo sentido ético que nos anima: a afirmação da vida. Uma educação do lugar deve ter a potência de transformação que abra clareiras de vida na cidade, que constitui lugares na cultura. Lugares que possam nos ensinar a singularidade, a alteridade, a confiança e o acolhimento: amar o devir, amar a transmutação, amar o estranhamento, ousar correr o risco de afirmar a vida.

As redes podem ser sonoras, verbais, discursivas, simbólicas, transferenciais, culturais, afetivas... Enfim, há uma infinidade de possibilidades e de nomeações. Entretanto, serão sempre redes cuja tessitura se faz por atos de encontro, atos de conexão e interação. Se estas redes efetivamente produzem cidades, o índice que podemos adotar é o dos efeitos destes atos a posteriori, do ponto de vista ético e de afirmação da vida. Assim, a educação do lugar, pedagogia da cidade, é entendida como forma de operar redes na cultura, na cidade, no cotidiano, implicando atos de encontro, constituindo uma bio (zoe) e micro política.

\section{Referências}

1. Ceccim RB. Criança hospitalizada: a atenção integral como uma escuta à vida. In: Ceccim RB, Carvalho PRA (Orgs.). Criança hospitalizada: atenção integral como escuta à vida. Porto Alegre: UFRGS; 1997: 27-41.

2. Merhy EE. Os Caps e seus trabalhadores: no olho do furacão antimanicomial alegria e alívio como dispositivos analisadores. In Merhy EE, Amaral H (Orgs.), A reforma psiquiátrica no cotidiano II. São Paulo: Aderaldo \& Rothschild; 2007: 25-56.

3. Brissac N. As máquinas de guerra contra os aparelhos de captura: uma fotonovela sci-fi. Artecidadezonaleste - Arte/cidade: intervenções urbanas. São Paulo: Editora Senac; 2002. 
Artigo de Opinião

4. Azevedo RM. Uma Idéia de metrópole no século XIX. Revista Brasileira de História, 1998; 18(35): 165-183.

5. Jacques PB. Elogio aos errantes: a arte de se perder na cidade. In: Jeudy HP, Jacques PB (Orgs.). Corpos e cenários urbanos, v. 1. Salvador: Edufba; 2006: 117-139.

${ }^{6}$. Cabral KV. Acompanhamento terapêutico como dispositivo da reforma psiquiátrica: considerações sobre o setting. Dissertação de Mestrado, Programa de Pós-Graduação em Psicologia Social e Institucional, Universidade Federal do Rio Grande do Sul, Porto Alegre; 2005.

7. Negri A. Para uma definição ontológica da multidão. Lugar Comum - estudos de mídia, cultura e democracia, 19 e 20; 2004: 15-26.

${ }^{8}$. Ceccim RB. Reforma geral da subjetividade: por uma educação rizomática da saúde mental - Prefácio. In: Fonseca TMG, Engelman S, Perrone CM (Orgs.). Rizomas da reforma psiquiátrica: a difícil reconciliação Porto Alegre: Sulina; 2007: 11-17. 